\title{
Role of Surfactants on Dissolution Behavior of Tamoxifen
}

Tuba Incecayir*, Seval Olgac, Duygu Yilmaz Usta, and Zeynep Safak Teksin

Department of Pharmaceutical Technology, Faculty of Pharmacy, Gazi University, Ankara, Turkey

e-mail: tincecayir@gazi.edu.tr

\section{ABSTRACT}

Because drug-surfactant interactions are specific, careful choice of surfactant media is required to develop dissolution tests for Biopharmaceutics Classification System (BCS) Class II drugs. The purpose of this study was to investigate the effects of cationic hexadecyltrimethylammonium bromide (CTAB) and nonionic surfactants (polysorbate 80 ) on the dissolution of bioequivalent immediate-release formulations of a BCS Class II anticancer drug, tamoxifen citrate (TMX), and to identify the most suitable surfactant medium reflecting the formulation differences and in vivo dissolution of the drug. Dissolution behaviors of the reference and test products were studied using USP apparatus II at pH 1.2, 4.5, and 6.8 with and without surfactant. At $\mathrm{pH} 6.8$, the effects of $0.5 \%(\mathrm{w} / \mathrm{v}) \mathrm{CTAB}$ and $0.5 \%(\mathrm{w} / \mathrm{v})$ polysorbate 80 on dissolution of the formulations were much more pronounced compared to $\mathrm{pH}$ 1.2. Based on model-dependent and modelindependent approaches, test products were found to be different from the reference in all surfactant media. Overall, none of the surfactant media reflected the bioequivalence of test products to the reference; however, polysorbate 80 may provide a discriminative test for certain formulation changes, and it may be physiologically meaningful to mimic in vivo solubilization and sink conditions due to continuous intestinal absorption of TMX.

KEYWORDS: Dissolution, solubility, surfactant, tamoxifen, BCS class II

\section{INTRODUCTION}

he Biopharmaceutics Classification System (BCS), which is the scientific framework for classifying drugs based on their aqueous solubility and intestinal permeability, has been an important tool for waiving the regulatory requirement for in vivo bioavailability (BA) and/or bioequivalence (BE) studies in both new and generic drug development $(1,2)$. Currently, the U.S. Food and Drug Administration (FDA) and European Medicine Agency (EMA) support the BCS as a scientific approach to permit a waiver of in vivo $B E$ testing for immediate release (IR) solid dosage forms for Class I (high solubility-high permeability) and Class III (high solubility-low permeability) drugs based on in vitro dissolution profile similarity of a drug product $(3$, 4). Current regulations do not allow biowaivers of Class II drugs (low solubility-high permeability); however, the World Health Organization (WHO) further considers biowaivers of certain Class II drugs such as diclofenac, ibuprofen, ketoprofen, verapamil, and piroxicam (5-9). For BCS Class II drugs, dissolution can be the rate-limiting step of drug absorption (10). Therefore, a mechanistic understanding of the correlation between in vitro dissolution and in vivo performance is a challenge (11, 12). It is also a challenge to develop an appropriate in vitro

\footnotetext{
* Corresponding author.
}

Dissolution

Technologies MAY 2021

www.dissolutiontech.com dissolution test for BCS Class II drug products for quality control (QC) purposes and drug product development, as well as for the establishment of biorelevance to forecast the in vivo performance during drug development. Since the $\mathrm{pH}$ and composition of the dissolution medium are of great impact on the dissolution process of poorly soluble drugs, in such cases synthetic surfactants may be used to increase drug solubility and dissolution and provide sink conditions in dissolution tests $(13,14)$.

The purpose of this study was to investigate the effects of different types of surfactants (cationic and nonionic) on the solubility of tamoxifen citrate (TMX) and the dissolution of its IR tablets, and to identify the most suitable surfactant medium for dissolution testing to reflect the formulation differences and in vivo dissolution of the drug. Being a BCS Class II weak base, TMX (2-[4-[(Z)-1,2-diphenylbut-1-enyl] phenoxy]-N,N dimethylethanamine; 2-hydroxypropane1,2,3-tricarboxylic acid) (CAS 54965-24-1) was chosen as the model drug for the present study (15). TMX is a selective estrogen receptor modulator in breast cancer tissue, thereby reducing the risk of recurrence and mortality of breast cancer (16). In the present study, in vitro disintegration and dissolution behaviors of reference and test products were investigated to make a comparison 
of the bioequivalent products of TMX based on modeldependent and model-independent approaches. The in vitro dissolution data of reference and test products of TMX were modeled using DDSolver software.

\section{MATERIALS AND METHODS}

\section{Materials}

TMX was kindly supplied from Deva Holding A.S. (Istanbul, Turkey). Hexadecyltrimethylammonium bromide (CTAB), sodium hydroxide, and potassium dihydrogen phosphate were purchased from Sigma-Aldrich Chemie $\mathrm{GmbH}$ (Steinheim, Germany). Sodium acetate trihydrate and polyoxyethylene sorbitan monooleate (polysorbate 80) were from Merck Schuchardt OHG (Hohenbrunn, Germany). All other chemicals were of analytical reagent grade. Three commercial tamoxifen IR tablets were purchased from the local drug market in Turkey. Each tablet contains $15.2 \mathrm{mg}$ of TMX, which is equivalent to $10 \mathrm{mg}$ of tamoxifen. The following commercial IR tablets were tested: reference, batch no: NR789; test 1, batch no: A063103; test 2, batch no: T85025.

\section{Saturation Solubility Measurements}

Saturation solubility of TMX was determined in $\mathrm{pH} 1.2$ hydrochloric acid $(\mathrm{HCl})$ buffer, $\mathrm{pH} 4.5$ acetate $(22 \mathrm{mM})$, and $\mathrm{pH} 6.8$ phosphate buffers $(50 \mathrm{mM})$. For solubility determination, an excess amount of TMX was placed into each dissolution medium in a $10 \mathrm{~mL}$ volumetric flask and stirred with a magnetic bar at $37{ }^{\circ} \mathrm{C}$ for 24 h. Saturated solutions were filtered using a $0.45-\mu \mathrm{m}$ syringe filter (Minisart NY 25, Sartorius Stedim Biotech $\mathrm{GmbH}$, Goettingen, Germany). Drug concentrations were measured by UV spectrophotometry (Cary 60 UVVis, Agilent Technologies, USA). In addition, studies with surfactant were identically performed, but contained either CTAB or polysorbate $80(0.5 \% \mathrm{w} / \mathrm{v})$ in $\mathrm{pH} 1.2 \mathrm{HCl}$ and $\mathrm{pH} 6.8$ phosphate buffers. All solubility experiments were carried out in triplicate.

\section{Disintegration Test}

Tablets were tested for disintegration using DIST-3 Triple Basket Tablet Disintegration Tester (PharmaTest, Germany). The reference and test tablets were placed in $900 \mathrm{~mL}$ of $\mathrm{pH} 1.2$ disintegration medium at $37^{\circ} \mathrm{C}$ to assess the disintegration of IR tablets of TMX in gastric $\mathrm{pH}$. All disintegration experiments were carried out in triplicate. All data are presented as mean \pm SD.

\section{Dissolution Study}

Dissolution tests were carried out using Varian VK 7000 dissolution apparatus (Varian, Inc., USA). The reference and test tablets were placed in $900 \mathrm{~mL}$ of dissolution medium at $37^{\circ} \mathrm{C}$ using USP dissolution apparatus II, with the paddle rotating at $50 \mathrm{rpm}$; $\mathrm{pH} 1.2 \mathrm{HCl}, \mathrm{pH} 4.5$ acetate ( $22 \mathrm{mM}$ ) and $\mathrm{pH} 6.8$ phosphate buffers $(50 \mathrm{mM})$ were used as the dissolution medium. CTAB and polysorbate 80 were used as cationic and nonionic surfactants, respectively. To evaluate the effects of surfactants on drug dissolution, $0.5 \%(\mathrm{w} / \mathrm{v}) \mathrm{CTAB}$ or polysorbate 80 dissolved in $\mathrm{pH} 1.2 \mathrm{HCl}$ and $\mathrm{pH} 6.8$ phosphate buffers was used as the dissolution medium. An aliquot of medium was withdrawn at predetermined time intervals, and an equivalent amount of fresh medium was added. Withdrawn samples were filtered using a $0.45-\mu \mathrm{m}$ syringe filter (Minisart NY 25) and analyzed spectrophotometrically. All dissolution experiments were carried out in triplicate and mean cumulative percentages of drug dissolved from the tablets were plotted against time.

\section{Assay}

UV absorbance of the samples after appropriate dilution with the corresponding dissolution medium was determined at $275 \mathrm{~nm}$ by UV spectrophotometry. The amount of TMX was calculated using the respective calibration curves. Calibration plots were linear over a calibration range of $2-15 \mu \mathrm{g} / \mathrm{mL}\left(r^{2}=0.998-0.999\right)$. The within-day and between-day precisions expressed as the coefficient of variation were less than $1.0 \%$. Accuracy ranged from $97.6 \%$ to $101 \%$.

\section{Data Analysis}

Dose number $\left(D_{0}\right)$ was calculated from Eq. (1) for buffers with and without surfactant, where $M_{\mathrm{O}}$ is the highest dose of drug administered, $V_{0}$ is the initial gastric volume $(250 \mathrm{~mL}), C_{S}$ is the saturation solubility (11).

$$
D_{O}=M_{O} / C_{S} \times V_{O}
$$

The dissolution profile comparisons were carried out using both model-independent and model-dependent methods. The model-independent similarity test was used to determine similarity of drug products and compare dissolution profiles of reference and test products in different dissolution media with and without surfactant (17). Dissolution profile comparison was performed under identical conditions. The similarity factor $\left(f_{2}\right)$ was calculated according to Eq. (2):

$$
f_{2}=50 \log \frac{100}{\sqrt{1+\frac{1}{n} \sum_{t=1}^{n}\left(R_{t}-T_{t}\right)^{2}}},
$$

where $R t$ and $T t$ are the cumulative percentage dissolved at time point $t$ for the reference and test products, respectively, and $n$ is the number of sampling points. The obtained $f_{2}$ values greater than 50 indicate similarity of two profiles, with the assumption of maximum allowable 
coefficient of variance of $20 \%$ at the earlier time points and $10 \%$ at other time points. The number of sample points was limited to not more than one, once the reference and test products reached $85 \%$ dissolution.

The model-dependent approach was used to assess the dissolution data using Microsoft Excel (2013) with the DDSolver add-in. The freely available DDSolver is a menudriven add-in program for Microsoft Excel written in Visual Basic for dissolution profile data analysis (18). Model fitting was used to determine drug release mechanisms of reference and test formulations using 23 different built-in models in DDSolver's library. Statistical analyses were performed using the DDSolver. The adjusted coefficient of determination $\left(R^{2}{ }_{\text {adj }}\right)$, Akaike information criterion (AIC), and model selection criterion (MSC) were used to determine the most appropriate release model. The model with the lowest AIC and highest MSC and $R^{2}$ adj was considered to be the most appropriate model. When a test product had similar values of statistical criteria for more than one model, the most appropriate model was selected based on its similarity to reference in terms of the kinetic model. The derived parameters of the models were employed for the t-test to compare the profiles of reference and test product using SPSS 16.0 (SPSS Inc.) when necessary. Differences were considered statistically significant at $p<0.05$.

\section{RESULTS}

\section{Effects of Surfactants on Solubility}

Saturation solubility values of TMX at different $\mathrm{pH}$ values and surfactant media are presented in Figure 1. Solubility of TMX increased substantially as $\mathrm{pH}$ increased from 1.2 to 4.5 (from $20 \pm 1.8 \mu \mathrm{g} / \mathrm{mL}$ to $126 \pm 4.4 \mu \mathrm{g} / \mathrm{mL}$ ), and it decreased as $\mathrm{pH}$ further increased, giving low solubility at $\mathrm{pH} 6.8(8.9 \pm 2.5 \mu \mathrm{g} / \mathrm{mL})$. CTAB exhibited the largest solubilization effect at $\mathrm{pH}$ 6.8. The surfactant media provided the sink condition at $\mathrm{pH} 1.2$ and 6.8. Therefore, $0.5 \%(\mathrm{w} / \mathrm{v})$ surfactant (CTAB or polysorbate 80 ) was used in dissolution medium at $\mathrm{pH} 1.2$ and 6.8 for the dissolution of 15.2-mg TMX tablets.

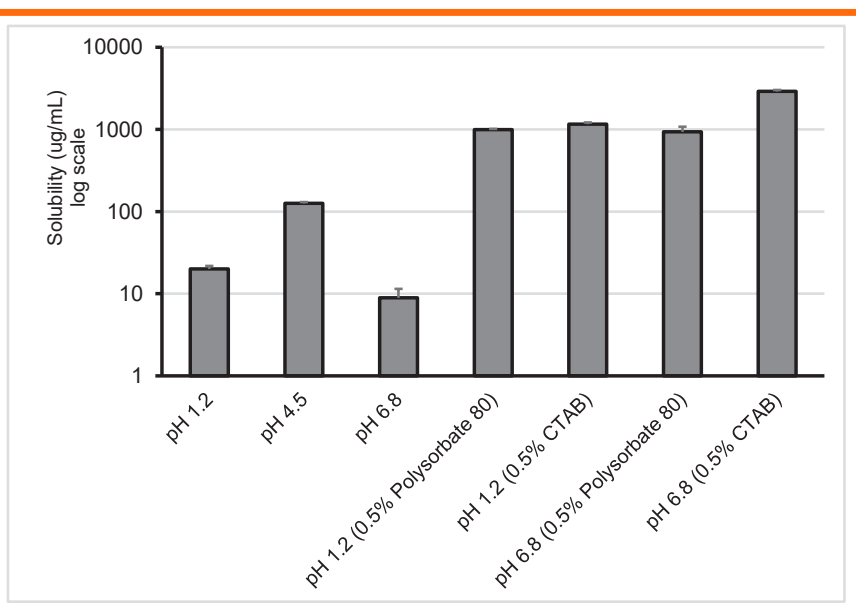

Figure 1. Saturation solubility (mean $\pm S D$ ) of tamoxifen citrate $(T M X)$ in buffers at different $\mathrm{pH}$ levels and surfactant medium at $37^{\circ} \mathrm{C}(n=3)$. $C T A B$, hexadecyltrimethylammonium bromide.

Saturation solubility values, calculated dose numbers $\left(D_{\mathrm{O}}\right)$, and relative sink conditions $\left(C_{\mathrm{S}} / C_{\mathrm{D}}\right)$ in the buffers of different $\mathrm{pH}$ levels and surfactant media are presented in Table 1. The ratio of saturation solubility to drug concentration was calculated by dividing the dose by $900 \mathrm{~mL}$ of dissolution medium $\left(C_{S} / C_{D}\right)$ to represent the closeness to the sink condition. The $C_{S} / C_{D}$ values greater than 3 are considered to provide sink conditions (19). The surfactant (CTAB or polysorbate 80 ) provided the sink condition at $\mathrm{pH} 1.2$ and 6.8. $D_{\mathrm{O}}$ was close to one at $\mathrm{pH}$ 4.5 , whereas the values were greater than one at $\mathrm{pH} 1.2$ and 6.8 media (6.08 and 13.7, respectively).

\section{Disintegration Test}

Disintegration times for the reference and test products are presented in Table 2. The mean disintegration of

Table 1. Saturation Solubility Values, Dose Numbers $\left(D_{O}\right)$ and Relative Sink Conditions $\left(C_{S} / C_{D}\right)$ of Tamoxifen Citrate (TMX) in Buffers and Surfactant Media

\begin{tabular}{|c|c|c|c|}
\hline Medium & $C_{\mathrm{s}}^{\mathrm{a}}(\mathrm{mg} / \mathrm{mL})$ & $D_{0}{ }^{b}$ & $C_{S} / C_{D}{ }^{c}$ \\
\hline pH $1.2 \mathrm{HCl}$ buffer & 0.020 & 6.08 & 1.18 \\
\hline pH $1.2 \mathrm{HCl}$ buffer with $0.5 \%(\mathrm{w} / \mathrm{v})$ polysorbate 80 & 0.994 & 0.122 & 58.9 \\
\hline pH $1.2 \mathrm{HCl}$ buffer with $0.5 \%(\mathrm{w} / \mathrm{v})$ CTAB & 1.16 & 0.105 & 68.6 \\
\hline pH 4.5 acetate buffer & 0.126 & 0.965 & 7.46 \\
\hline pH 6.8 phosphate buffer & 0.0089 & 13.6 & 0.527 \\
\hline pH 6.8 phosphate buffer with $0.5 \%(\mathrm{w} / \mathrm{v})$ polysorbate 80 & 0.933 & 0.130 & 55.2 \\
\hline pH 6.8 phosphate buffer with $0.5 \%(\mathrm{w} / \mathrm{v})$ CTAB & 2.90 & 0.042 & 172 \\
\hline
\end{tabular}

${ }^{a}$ Saturation solubility $\left(C_{S}\right)$ values of $T M X$.

${ }^{b}$ Dose numbers $\left(D_{o}\right)$ calculated based on the highest dose strength. The highest dose strength contains $30.4 \mathrm{mg}$ of TMX, which is equivalent to $20 \mathrm{mg}$ tamoxifen.

${ }^{c}$ Relative sink conditions $\left(C_{S} / C_{D}\right)$ for IR tablets of $15.2 \mathrm{mg}$ of $T M X$, which is equivalent to $10 \mathrm{mg}$ tamoxifen.

$\mathrm{HCl}$, hydrochloric acid; CTAB, hexadecyltrimethylammonium bromide; IR, immediate release. 
reference (26 $\mathrm{min}$ ) was considerably slower compared to the test products (2.8 and 10.6 min for test 1 and 2, respectively). The reference and test 2 products are filmcoated IR tablets, whereas test 1 is not.

Table 2. Disintegration Times for Reference and Test Products of Immediate-Release Tamoxifen Citrate (TMX) Tablets

\begin{tabular}{|l|c|}
\hline Tablet & $\begin{array}{c}\text { Disintegration Time, mean } \pm \text { SD } \\
(\boldsymbol{n}=\mathbf{3})\end{array}$ \\
\hline Reference Product & $26 \pm 8.6 \mathrm{~min}$ \\
\hline Test Product 1 & $2.8 \pm 0.4 \mathrm{~min}$ \\
\hline Test Product 2 & $10.6 \pm 1.4 \mathrm{~min}$ \\
\hline
\end{tabular}

\section{Surfactant Mediated Dissolution}

Comparison of dissolution profiles of reference and test products in buffers with different $\mathrm{pH}$ values, as well as in the surfactant media, are presented in Figure 2. Table 3 summarizes the calculated $f_{2}$ values for the test products versus reference product in different media with and without surfactant. The dissolution profiles of test products were different from that of reference $\left(f_{2}\right.$ $<50)$ in all media, except for $\mathrm{pH} 6.8$ buffer for test $1\left(f_{2}\right.$ $=54.9)$. In pH 1.2 buffer, the amount of drug dissolved from the reference and test products was variable $(51 \%$, $102 \%$, and $83 \%$ in $2 \mathrm{~h}$ for reference, test 1 , and test 2 , respectively). When $0.5 \%(\mathrm{w} / \mathrm{v})$ CTAB was added to $\mathrm{pH}$ 1.2 medium, test 1 and 2 completely dissolved in 30 and $45 \mathrm{~min}$, respectively. The extent of dissolution of test 1 (completely dissolved in $20 \mathrm{~min}$ ) and the reference increased when $0.5 \%(\mathrm{w} / \mathrm{v})$ polysorbate 80 was added to the $\mathrm{pH} 1.2$ medium. The dissolution rate or extent did not increase for the reference in CTAB containing $\mathrm{pH} 1.2$ medium, and for test 2 in polysorbate 80 containing $\mathrm{pH}$ 1.2 medium.

Dissolution of test formulations was rapid in the $\mathrm{pH} 4.5$ acetate buffer ( $>85 \%$ in $20 \mathrm{~min}$ ); however, the dissolution rate and extent of the reference were lower compared to the test products, probably due to longer disintegration time of the reference. At $\mathrm{pH} 4.5$, test 1 had a similar release profile to test $2\left(f_{2}=51.3\right)$, while both test products were different from the reference $\left(f_{2}<50\right)$. As a result of low solubility at $\mathrm{pH} 6.8,47.7 \%, 42.6 \%$, and $22.8 \%$ of the labeled amount was dissolved within $1.5 \mathrm{~h}$ from reference, test 1 , and 2 , respectively. Interestingly, the dissolution extent of the reference at $\mathrm{pH} 1.2$ and 6.8 were comparable (51.1\% vs. $47.7 \%)$, and only test 1 exhibited a similar dissolution profile to the reference at $\mathrm{pH} 6.8$ $\left(f_{2}=54.9\right)$. Dissolution rates and extents significantly increased when CTAB was added to dissolution medium at $\mathrm{pH}$ 6.8. The dissolution extent of reference and test 1 increased to $86.8 \%$ and $74.6 \%$ in $1.5 \mathrm{~h}$, respectively, and test 2 completely dissolved in $20 \mathrm{~min}$. In polysorbate 80 containing pH 6.8 medium, in which the rates and extents of dissolution were highest, test 1 exhibited dissolution profile similarity to test $2\left(f_{2}=61.1\right)$; however, both test products differed from the reference in polysorbate 80 containing $\mathrm{pH} 6.8$ medium $\left(f_{2}<50\right)$. At pH 6.8, the effects of $C T A B$ and polysorbate 80 on dissolution of the formulations were much more pronounced compared to $\mathrm{pH} 1.2$.

Table 3. Similarity Factor $\left(f_{2}\right)$ Values for Immediate-Release Tamoxifen Citrate (TMX) Test Products Versus Reference Product in Buffers With and Without Surfactant

\begin{tabular}{|l|c|c|}
\hline Medium & Test $1 f_{2}$ & Test $2 f_{2}$ \\
\hline pH 1.2 HCl buffer & 17.9 & 25.6 \\
\hline $\begin{array}{l}\text { pH } 1.2 \mathrm{HCl} \text { buffer with } \\
0.5 \% \text { CTAB }\end{array}$ & 8.81 & 14.4 \\
\hline $\begin{array}{l}\text { pH } 1.2 \mathrm{HCl} \text { buffer } \\
0.5 \% \text { polysorbate } 80\end{array}$ & 12.2 & 43.8 \\
\hline pH 4.5 acetate buffer & 23.8 & 27.8 \\
\hline $\begin{array}{l}\text { pH } 6.8 \text { phosphate } \\
\text { buffer }\end{array}$ & 54.9 & 27.7 \\
\hline $\begin{array}{l}\text { pH } 6.8 \text { phosphate } \\
\text { buffer with 0.5\% CTAB }\end{array}$ & 35.2 & 19.5 \\
\hline $\begin{array}{l}\text { pH 6.8 phosphate } \\
\text { buffer with 0.5\% } \\
\text { polysorbate 80 }\end{array}$ & 29.0 & 29.2 \\
\hline
\end{tabular}

$f_{2}<50$ indicates a difference; $f_{2} \geq 50-100$ indicates similarity. CTAB,

hexadecyltrimethylammonium bromide.

\section{Model Fitting with DDSolver}

The suitable mathematical models were obtained via DDSolver. The model parameters and goodness of fit results for the reference and test products of TMX are presented in Table 4 . The same models were successfully used to model the reference and test 1 at $\mathrm{pH} 1.2$ with and without $\mathrm{CTAB}$, and the reference and test 2 at $\mathrm{pH} 1.2$ with polysorbate 80 . Model fitting of reference and test products produced good fits for the same model in each $\mathrm{pH} 4.5$ and 6.8 media with and without surfactant.

\section{DISCUSSION}

Synthetic surfactants may be used to provide sufficient drug solubility and sink conditions in dissolution tests for poorly water-soluble drugs. Since drug-surfactant interactions are specific, the dissolution profiles of poorly soluble acidic and basic drugs are influenced by the class of surfactant added to the dissolution medium (20). Therefore, there is a need for careful choice of surfactant media to perform the dissolution studies of poorly soluble drugs. In the present study, the effects of $\mathrm{pH}$ and surfactants on the dissolution profiles of innovator and generic products of TMX were investigated. 


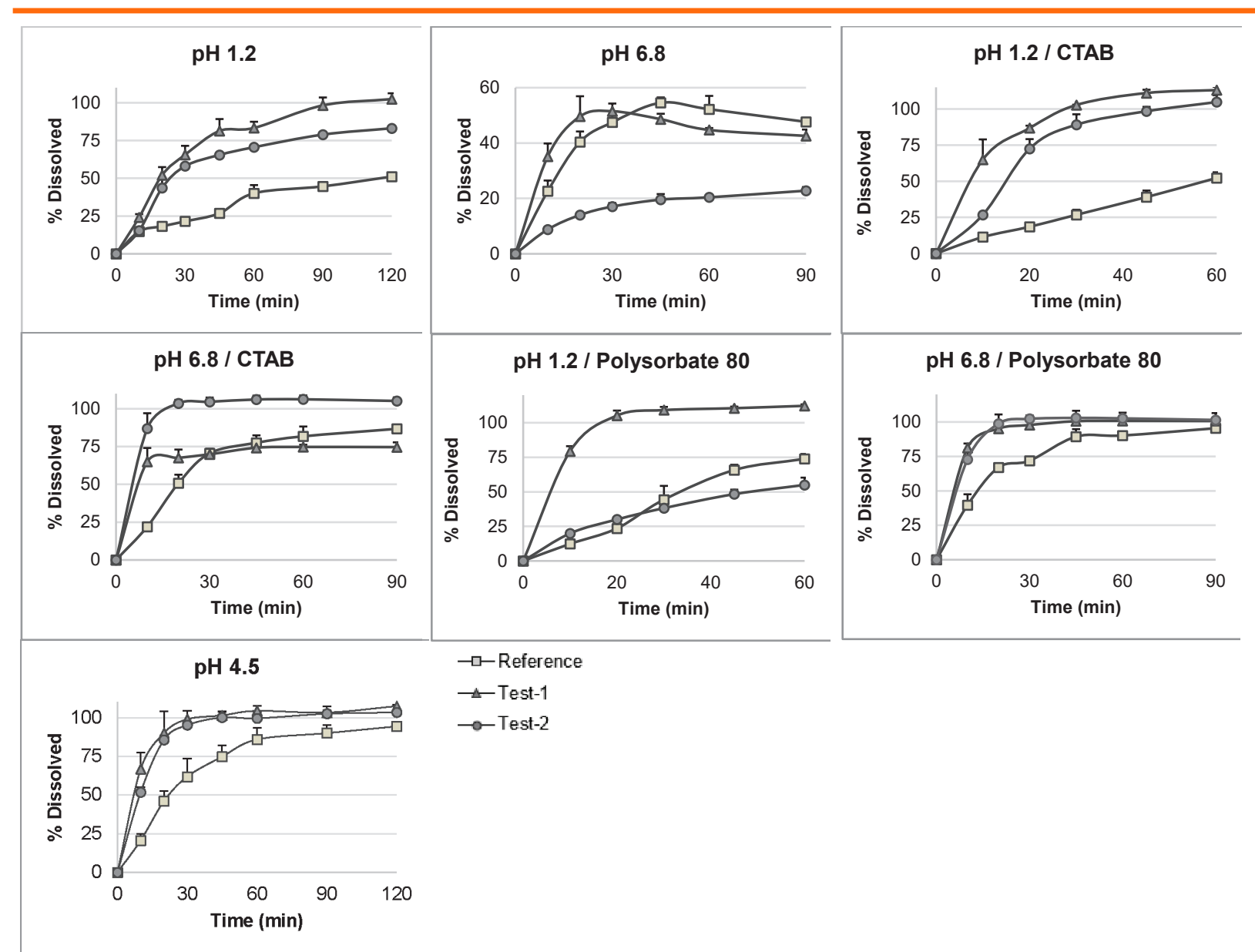

Figure 2. Dissolution profiles (mean $\pm S D$ ) of reference and test products of tamoxifen citrate (TMX) in pH 1.2 hydrochloric acid, pH 4.5 acetate, and $\mathrm{pH} 6.8$ phosphate buffers and in surfactant media at $\mathrm{pH} 1.2$ and 6.8 buffers $(n=3)$. CTAB, hexadecyltrimethylammonium bromide.

Tamoxifen was selected as the model compound based on its lipophilic characteristics and poor solubility in water. Furthermore, reference and two multisource bioequivalent products available on the Turkish drug market were used to make a comparison. TMX is a basic compound with a molecular weight of $563.6 \mathrm{~g} / \mathrm{mol}$, and an acid dissociation constant (pKa) of 8.85 (21). Tamoxifen free base is highly hydrophobic according to the value of the logarithm of the octanol/water partition coefficient ( $\log P=6.64)$ with low solubility in water $(0.4 \mu \mathrm{g} / \mathrm{mL})$ (22). Commercially, it is converted to the citrate salt to increase the aqueous solubility and therapeutic efficacy. However, the increase in its solubility via salt formation is limited, which inhibits the dissolution rate of its solid oral formulations.

Being an ionizable basic compound, TMX demonstrated a $\mathrm{pH}$-dependent solubility with a low solubility at high $\mathrm{pH} 6.8(8.9 \mu \mathrm{g} / \mathrm{mL})$. On the other hand, the unionized fraction of TMX increases as $\mathrm{pH}$ increases in the intestine, explaining its high intestinal permeability. According to the current guidelines for the BCS-based biowaivers,
TMX is classified as a poorly soluble drug based on the solubility of its highest dose strength $(30.4 \mathrm{mg}$ of TMX, which is equivalent to $20 \mathrm{mg}$ of tamoxifen) in $250 \mathrm{~mL}$ of aqueous media over the $\mathrm{pH}$ range of $1.0-6.8$ at $37{ }^{\circ} \mathrm{C}$ $(3,4)$. Furthermore, based on the lately suggested BCS subclassification (10), TMX can be subclassified as a BCS Class Ilb weak base. However, a significant increase in the solubility of TMX was observed in $\mathrm{pH} 4.5$ acetate buffer compared to $\mathrm{pH} 1.2 \mathrm{HCl}$ buffer in the present study. This finding has been reported elsewhere, where acetic acid resulted in a significant increase in the aqueous solubility of weak bases due to the formation of highly soluble acetate salt $(20,23)$.

In the present study, $D_{0}$ values of TMX were found to be greater than 1 at $\mathrm{pH} 1.2$ and 6.8. Dissolution of TMX was not complete at $\mathrm{pH} 1.2$ for the reference and test 2, although test 1 completely dissolved in $\mathrm{HCl}$ buffer within $90 \mathrm{~min}$. This result may be associated with longer disintegration times of the reference and test 2 products compared to test 1 ( 26 and $10.6 \mathrm{~min}$ vs. $2.8 \mathrm{~min}$, respectively). In pH 4.5 acetate buffer, the dissolution rate 
Table 4. In Vitro Dissolution Data Modeling of Reference and Test Formulations of Tamoxifen Citrate (TMX)

\begin{tabular}{|c|c|c|c|c|}
\hline \multicolumn{2}{|l|}{ Dissolution Medium } & Reference Product & Test Product 1 & Test Product 2 \\
\hline \multirow[t]{3}{*}{ pH 1.2 HCl Buffer } & Model* & Weibull-2 $^{\mathrm{a}}$ & Weibull-2 $^{\mathrm{b}}$ & Gompertz-2 \\
\hline & Parameter & $\begin{array}{l}\alpha=32.1 \\
\beta=0.647\end{array}$ & $\begin{array}{l}\alpha=46.5^{\ddagger} \\
\beta=1.14^{\ddagger}\end{array}$ & $\begin{array}{l}\alpha=42.4 \\
\beta=3.12 \\
F_{\max }=87.3\end{array}$ \\
\hline & $\begin{array}{r}R_{\text {adj }}^{2} \\
\text { AIC } \\
\text { MISC }\end{array}$ & $\begin{array}{l}0.971 \\
35.5 \\
2.74\end{array}$ & $\begin{array}{l}0.991 \\
38.3 \\
3.75\end{array}$ & $\begin{array}{l}0.994 \\
32.9 \\
4.10\end{array}$ \\
\hline \multirow[t]{3}{*}{ pH $1.2 \mathrm{HCl}$ buffer with $0.5 \%$ CTAB } & Model* & Peppas-Sahlin-2 & Peppas-Sahlin-2 $^{\mathrm{c}}$ & Gompertz-2 \\
\hline & Parameter & $\begin{array}{l}\mathrm{k}_{1}=0.881 \\
\mathrm{k}_{2}=0.748\end{array}$ & $\begin{array}{l}k_{1}=26.0^{\ddagger} \\
k_{2}=-1.44^{\ddagger}\end{array}$ & $\begin{array}{l}\alpha=96.6 \\
\beta=4.18 \\
F_{\max }=110\end{array}$ \\
\hline & $\begin{array}{r}R_{\text {adj }}^{2} \\
\text { AIC } \\
\text { MISC }\end{array}$ & $\begin{array}{l}0.998 \\
8.70 \\
5.63\end{array}$ & $\begin{array}{l}0.996 \\
23.8 \\
3.99\end{array}$ & $\begin{array}{l}0.999 \\
17.1 \\
5.62\end{array}$ \\
\hline \multirow{3}{*}{$\begin{array}{l}\text { pH } 1.2 \mathrm{HCl} \text { buffer with } 0.5 \% \\
\text { polysorbate } 80\end{array}$} & Model* & Logistic-1 & Peppas-Sahlin-1 & Logistic- $^{d}$ \\
\hline & Parameter & $\begin{array}{l}\alpha=-5.99 \\
\beta=3.91\end{array}$ & $\begin{array}{l}\mathrm{k}_{1}=37.9 \\
\mathrm{k}_{2}=-3.12 \\
\mathrm{~m}=0.450\end{array}$ & $\begin{array}{l}\alpha=-3.62^{\ddagger} \\
\beta=2.16 \ddagger\end{array}$ \\
\hline & $\begin{array}{r}R^{2} \text { adj } \\
\text { AIC } \\
\text { MISC } \\
\end{array}$ & $\begin{array}{l}0.990 \\
31.6 \\
3.87 \\
\end{array}$ & $\begin{array}{l}0.991 \\
34.9 \\
2.67 \\
\end{array}$ & $\begin{array}{l}0.997 \\
17.3 \\
4.94 \\
\end{array}$ \\
\hline \multirow[t]{3}{*}{ pH 4.5 acetate buffer } & Model* & Logistic-1 & Logistic-1 $^{\mathrm{e}}$ & Logistic-1 ${ }^{f}$ \\
\hline & Parameter & $\begin{array}{l}\alpha=-5.15 \\
\beta=3.82\end{array}$ & $\begin{array}{l}\alpha=-7.35^{\ddagger} \\
\beta=7.82^{\ddagger}\end{array}$ & $\begin{array}{l}\alpha=-7.04^{\ddagger} \\
\beta=6.92^{\ddagger}\end{array}$ \\
\hline & $\begin{array}{r}R_{\text {adj }}^{2} \\
\text { AIC } \\
\text { MISC }\end{array}$ & $\begin{array}{l}0.999 \\
20.4 \\
5.96\end{array}$ & $\begin{array}{l}0.983 \\
43.4 \\
2.27\end{array}$ & $\begin{array}{l}0.994 \\
35.1 \\
3.60 \\
\end{array}$ \\
\hline \multirow[t]{3}{*}{ pH 6.8 phosphate buffer } & Model* & Peppas-Sahlin-2 & Peppas-Sahlin-2 & Peppas-Sahlin-2 \\
\hline & Parameter & $\begin{array}{l}k_{1}=12.1 \\
k_{2}=-0.714\end{array}$ & $\begin{array}{l}k_{1}=15.5^{\ddagger} \\
k_{2}=-1.19^{\ddagger}\end{array}$ & $\begin{array}{l}k_{1}=3.69^{\ddagger} \\
k_{2}=-0.132^{\ddagger}\end{array}$ \\
\hline & $\begin{array}{r}R_{\text {adj }}^{2} \\
\text { AIC } \\
\text { MISC }\end{array}$ & $\begin{array}{l}0.939 \\
37.5 \\
1.46\end{array}$ & $\begin{array}{l}0.968 \\
31.6 \\
1.55\end{array}$ & $\begin{array}{l}0.988 \\
13.5 \\
3.18\end{array}$ \\
\hline \multirow{3}{*}{$\begin{array}{l}\text { pH } 6.8 \text { phosphate buffer with } 0.5 \% \\
\text { CTAB }\end{array}$} & Model* & Gompertz-2 & Gompertz-2 $^{\mathrm{h}}$ & Gompertz-2 ${ }^{i}$ \\
\hline & Parameter & $\begin{array}{l}\alpha=49.7 \\
\beta=3.50 \\
F_{\max }=91.1\end{array}$ & $\begin{array}{l}\alpha=1.10^{\ddagger} \\
\beta=1.66^{\ddagger} \\
F_{\text {max }}=78.5^{\ddagger}\end{array}$ & $\begin{array}{l}\alpha=0.730^{\ddagger} \\
\beta=1.49^{\ddagger} \\
F_{\max }=112^{\ddagger}\end{array}$ \\
\hline & $\begin{array}{r}R_{\text {adj }}^{2} \\
\text { AIC } \\
\text { MISC }\end{array}$ & $\begin{array}{l}0.996 \\
26.2 \\
4.42\end{array}$ & $\begin{array}{l}0.997 \\
20.8 \\
3.58 \\
\end{array}$ & $\begin{array}{l}0.987 \\
36.6 \\
2.12 \\
\end{array}$ \\
\hline \multirow{3}{*}{$\begin{array}{l}\text { pH } 6.8 \text { phosphate buffer with } 0.5 \% \\
\text { polysorbate } 80\end{array}$} & Model* & Probit-1 & Probit-1 ${ }^{j}$ & Probit-1 ${ }^{k}$ \\
\hline & Parameter & $\begin{array}{l}\alpha=-2.30 \\
\beta=2.05\end{array}$ & $\begin{array}{l}\alpha=-1.48^{\ddagger} \\
\beta=2.39^{\ddagger}\end{array}$ & $\begin{array}{l}\alpha=-4.88^{\ddagger} \\
\beta=5.49^{\ddagger}\end{array}$ \\
\hline & $\begin{array}{r}R^{2}{ }_{\text {adj }} \\
\text { AIC } \\
\text { MISC }\end{array}$ & $\begin{array}{l}0.993 \\
30.1 \\
3.67\end{array}$ & $\begin{array}{l}0.999 \\
13.6 \\
5.31\end{array}$ & $\begin{array}{l}0.997 \\
26.1 \\
3.80\end{array}$ \\
\hline
\end{tabular}

Model fitting via DDSolver also produced good fits to: ${ }^{a}$ Higuchi and Peppas-Sahlin-2; ${ }^{b}$ Probit-2; ${ }^{c}$ Weibull-3; ${ }^{d}$ Weibull-2; ${ }^{e}$ Gompertz-2; ${ }^{f}$ Probit-1; ${ }^{g}$ Weibull-4; ${ }^{h}$ Logistic-1 and Gompertz-1; 'Weibull-4; 'Weibull-2; ${ }^{k}$ Weibull-2 models. ${ }^{*}$ See ref 18 for further description of the models; ${ }^{*}$ model parameters were significantly different from those of reference $(p<0.05)$.

and extent of the reference were also lower compared to the test products, which may also be associated with longer disintegration time of the reference. Dissolution of TMX was not complete at $\mathrm{pH} 6.8$ for the reference and both test formulations. Interestingly, the total dissolved amounts for the reference and test 2 in $\mathrm{pH} 1.2$ and $\mathrm{pH} 6.8$ indicated complete dissolution, suggesting that dissolution is likely to be complete within the 
gastrointestinal tract, and the drug is likely present in a supersaturated state in the small intestine. Drugs can be well-absorbed across the intestinal mucosa during this supersaturation state (24). It is clear that in vivo solubility, which is the key determinant for in vivo BA, is different from in vitro solubility, because solubility in the intestine is affected by $\mathrm{pH}$ and physiology of the absorption site (25).

In vivo dissolution of poorly soluble drugs can also be further complicated by the formulation factors, such as particle properties and polymorphic transformation of active pharmaceutical ingredient, as well as the pharmaceutical excipients and manufacturing processes. In the present study, data related to the formulation details were not available to make a further comparison in terms of formulation factors. Two generic products on the drug market, which are essentially bioequivalent to the reference product of TMX, were compared with the reference using in vitro dissolution test. Cationic and nonionic surfactants were used as different dissolution media. No anionic surfactant (sodium lauryl sulfate, SLS) was tested in the present study due to a potential interaction between negatively charged SLS and the cationic tamoxifen, probably resulting in a complex and noticeable decrease in the dissolution rates. A similar result was also reported between SLS and formulations of the weakly basic BCS Class II drug, carvedilol (20). Significantly enhanced solubility of TMX was observed due to the micellar solubilization at surfactant concentrations above the critical micelle concentration of each surfactant $(0.04 \%$ and $0.007 \%$ for CTAB and polysorbate 80 , respectively) in $\mathrm{pH} 1.2$ and 6.8 media (26). Polysorbate 80 increased the solubility of $T M X$ irrespective of $\mathrm{pH}$, whereas CTAB exhibited a 2.5 times larger solubilization effect at $\mathrm{pH} 6.8$ compared to $\mathrm{pH} 1.2$, probably due to the repulsion between similar charges of TMX and cationic surfactant at low pH. Thus, the extent of solubility enhancement depends on the pKa of the drug and ionic nature of the surfactant. A similar finding was reported for the relationship between carvedilol and nonionic/cationic surfactants (20).

Dissolution rate and extent of TMX test and reference products were significantly dependent on the type of surfactant used in the dissolution medium and the product itself, as previously reported for carvedilol (20). Dissolution rates of TMX from reference and test 1 were found to be slower in the presence of CTAB compared to polysorbate 80 at pH 1.2 and 6.8 media. Whereas for test 2, dissolution rates were either higher or similar in the presence of CTAB compared to polysorbate 80 at
pH 1.2 and 6.8 media, respectively. Because there is no difference between in vivo performance of the reference and test products, it would be a challenge to achieve similar dissolution profiles for the test formulations of TMX using surfactant containing dissolution medium. Over the last decades, biorelevant media containing bile salts (sodium taurocholate) and phospholipids (lecithin) have been widely studied for in vivo predictivity $(27,28)$. It was found to be beneficial to use synthetic surfactant media as surrogates for these complex and expensive biorelevant media to predict the absorption of some BCS Class II drugs $(20,29)$. Recently, among the other surfactant media, polysorbate 80 containing $\mathrm{pH} 6.8$ buffer was demonstrated to be the most biorelevant medium, which probably reflects the $\mathrm{BE}$ of generic products to the reference product of carvedilol based on in vitro dissolution profile similarity (20). On the other hand, the present study demonstrated that for TMX, none of the surfactant media reflected the BE of test products to the reference product. Both test products were different from the reference $\left(f_{2}<50\right)$ in all surfactant media. CTAB at $\mathrm{pH} 1.2$ and 6.8 and polysorbate 80 at pH 1.2 were not capable of correcting the over-discriminative tendency of simple buffers. However, polysorbate 80 at pH 6.8 presented a discriminative medium for the disintegration times of test 1 and 2, which were considerably lower than that of reference, as noted above. Test 1 also exhibited dissolution profile similarity to test 2 in polysorbate 80 medium at $\mathrm{pH} 6.8\left(f_{2}=61.1\right)$.

Quantitative evaluation of drug dissolution characteristics based on mathematical models has long been of great interest to pharmaceutical scientists. A wide variety of mathematical models have been developed to fit drug release data $(18,30,31)$. It is apparent that such methods are more complicated compared to model independent methods. This study identified and compared the most suitable models to fit the in vitro dissolution data of reference and test products of TMX using DDSolver, which is the first reported comprehensive and freely available add-in program to facilitate the modeling and comparison of dissolution data (18). Based on the criteria to evaluate model goodness of fit, the Weibull, Gompertz, Peppas-Sahlin, Logistic, and Probit models and derivatives were found to successfully fit each individual dissolution profiles of the test and reference in different media $\left(r^{2}\right.$ $=0.939-0.999, \mathrm{AIC}=8.7-43.4, \mathrm{MSC}=1.46-5.93)$. The Higuchi model demonstrated goodness of fit results similar to the Weibull-2 and Peppas-Sahlin-2 models for the reference product only at $\mathrm{pH} 1.2$, unlike other test products and cases. Model fitting of the reference and both test products produced good fits for the same 
model in each case in $\mathrm{pH} 4.5$ and 6.8 media. The same models were successfully used to model the reference and test 1 at $\mathrm{pH} 1.2$ with and without CTAB, and reference and test 2 at $\mathrm{pH} 1.2$ with polysorbate 80 . However, the model parameters of test products were found to be significantly different from those of reference $(p<0.05)$ in each case. Thus, it implies that the dissolution profiles of these test products were not like the profile of the reference product. The model-dependent approach also demonstrated that the dissolution profiles of reference and test products can be well-described by several different mathematical equations in some cases based on the AIC, MSC, and $R^{2}$ adj criteria. Therefore, it was found that no single method can be suggested as the best to fit these dissolution data, as pointed out by the others (30).

Pharmacokinetic data indicate that TMX is rapidly absorbed with peak plasma concentration occurring $0.92 \mathrm{~h}$ after oral administration (16). It is extensively metabolized to active metabolites by multiple CYP enzymes including CYP2D6, CYP3A4/5, CYP2C9, and CYP2C19 and eliminated via glucuronidation by UDPglucuronosyltransferases (UGTs) (32). Endoxifen is one of the most important metabolites in the efficacy of tamoxifen therapy (32). The half-lives of the drug and metabolite are approximately 4 and 9 days, respectively (33). Tamoxifen and its metabolites were found to be substrates for the efflux transporters, such as P-glycoprotein (P-gp) and multidrug resistance-associated protein (MRP) 2 (34). The response to tamoxifen has a high degree of interindividual variability. It seems that this high variability was due to the several pathways, including phase II enzymes, $A B C$ efflux transporters, and various CYP enzymes involving in its disposition rather than the dissolution process. However, gastric emptying and in vivo solubilization, which can be affected by the gastrointestinal variable factors such as food, bile salts, intestinal secretions, liquid volume, and $\mathrm{pH}$, may play a significant role for the intestinal absorption of TMX (35).

From a scientific point of view, being a BCS Class II drug, TMX is not a candidate for granting a biowaiver according to the current guidelines on waiver of in vivo BA and BE studies for IR solid oral dosage forms based on BCS. However, it may be a candidate for in vitro-in vivo correlation (IVIVC) and in vivo predictive dissolution approaches coupled with in silico models to predict the in vivo performance of poorly soluble oral drugs products $(36,37)$. Thus, it may provide reduced risks associated with product changes and in designing generic versions of existing drug products.

\section{CONCLUSION}

Overall, the present study indicated the need for carefully choosing surfactant media to develop dissolution tests of BCS Class II drugs for QC and in vivo prediction. In the case of TMX, polysorbate 80 may be added to dissolution medium to provide a discriminative test for certain formulation changes, and it may be physiologically meaningful to mimic in vivo solubilization and sink conditions owing to continuous intestinal absorption of TMX. The present study also identified and compared the most suitable models to fit the in vitro dissolution data of reference and test products of TMX in different $\mathrm{pH}$ and surfactant media. In general, the reference and test products produced good fits for the same model in most cases; however, the model parameters of test products were significantly different from those of reference $(p$ $<0.05$ ), which was further supported by the modelindependent $\left(f_{2}\right)$ results. It may be a challenge for future research to develop not only discriminatory but also biorelevant in vitro dissolution tests for the prediction of in vivo performance of oral IR TMX products.

\section{ACKNOWLEDGEMENTS}

We thank Deva Holding A.S. (Istanbul, Turkey) for providing tamoxifen citrate drug substance for research purposes. This research did not receive any other support from funding agencies in the public, commercial, or notfor-profit sectors. This study is based on a presentation at AAPS PharmSci 360 meeting, November 4-7, 2018.

\section{CONFLICT OF INTEREST}

The authors disclosed no conflicts of interest related to this article.

\section{REFERENCES}

1. Shah, V. P.; Amidon, G. L. G.L. Amidon, H. Lennernas, V.P. Shah, and J.R.Crison. A theoretical basis for a biopharmaceutic drug classification: the correlation of in vitro drug product dissolution and in vivo bioavailability. Pharm. Res. 12, 413-420, 1995backstory of BCS. AAPS J. 2014, 16, 894-898. DOI: 10.1208/ s12248-014-9620-9.

2. Davit, B. M.; Kanfer, I.; Tsang, Y. C.; Cardot, J.-M. BCS biowaivers: similarities and differences among EMA, FDA, and WHO requirements. AAPS J . 2016, 18, 612-618. DOI: 10.1208/ s12248-016-9877-2.

3. Waiver of In Vivo Bioavailability and Bioequivalence Studies for Immediate Release Solid Oral Dosage Forms Based on a Biopharmaceutics Classification System; Guidance for Industry. U.S. Department of Health and Human Services, Food and Drug Administration, Center for Drug Evaluation and Research (CDER), Silver Spring, MD, 2017.

4. Guideline on the Investigation of Bioequivalence; CPMP/EWP/ 
QWP/1401/98 Rev.1; Committee for Medicinal Products for Human Use, European Medicines Agency (EMA): London, 2010.

5. Vogelpoel, H.; Welink, J.; Amidon, G. L.; Junginger, H. E.; Midha, K. K.; Möller, H.; Olling, M.; Shah, V. P.; Barends, D. M. Biowaiver monographs for immediate release solid oral dosage forms based on biopharmaceutics classification system (BCS) literature data: verapamil hydrochloride, propranolol hydrochloride, and atenolol. J. Pharm. Sci. 2004, 93, 1945-1956. DOI: 10.1002/ jps.20131.

6. Potthast, H.; Dressman, J. B.; Junginger, H. E.; Midha, K. K.; Oeser, H.; Shah, V. P.; Vogelpoel, H.; Barends, D. M. Biowaiver monographs for immediate release solid oral dosage forms: ibuprofen. J. Pharm. Sci. 2005, 94, 2121-2131. DOI: 10.1002/ jps.20444.

7. Chuasuwan, B.; Binjesoh, V.; Polli, J. E.; Zhang, H.; Amidon, G. L.; Junginger, H. E.; Midha, K. K.; Shah, V. P.; Stavchansky, S.; Dressman, J. B.; Barends, D. M. Biowaiver monographs for immediate release solid oral dosage forms: diclofenac sodium and diclofenac potassium. J. Pharm. Sci. 2009, 98, 1206-1219. DOI: 10.1002/jps.21525.

8. Shohin, I. E.; Kulinich, J. I.; Ramenskaya, G. V.; Abrahamsson, B.; Kopp, S.; Langguth, P.; Polli, J. E.; Shah, V. P.; Groot, D. W.; Barends, D. M.; Dressman, J. B. Biowaiver monographs for immediaterelease solid oral dosage forms: ketoprofen. J. Pharm. Sci. 2012, 101, 3593-3603. DOI: 10.1002/jps.23233.

9. Shohin, I. E.; Kulinich, J. I.; Ramenskaya, G. V.; Abrahamsson, B.; Kopp, S.; Langguth, P.; Polli, J. E.; Shah, V. P.; Groot, D. W.; Barends, D. M.; Dressman, J. B. Biowaiver monographs for immediate release solid oral dosage forms: piroxicam. J. Pharm. Sci. 2014, 103, 367-377. DOI: 10.1002/jps.23799.

10. Tsume, Y.; Mudie, D. M.; Langguth, P.; Amidon, G. E.; Amidon, G. L. The Biopharmaceutics Classification System: subclasses for in vivo predictive dissolution (IPD) methodology and IVIVC. Eur. J. Pharm. Sci. 2014, 57, 152-163. DOI: 10.1016/j.ejps.2014.01.009.

11. Amidon, G. L.; Lennernäs, H.; Shah, V. P.; Crison, J. R. A theoretical basis for a biopharmaceutic drug classification: the correlation of in vitro drug product dissolution and in vivo bioavailability. Pharm. Res. 1995, 12,413-420. DOI: 10.1023/A:1016212804288.

12. Tubic-Grozdanis, M.; Bolger, M. B.; Langguth, P. Application of gastrointestinal simulation for extensions for biowaivers of highly permeable compounds. AAPS J. 2008, 10, 213-226. DOI: 10.1208/s12248-008-9023-x.

13. Shah, V. P.; Konecny, J. J.; Everett, R. L.; McCullough, B.; Noorizadeh, A. C.; Skelly, J. P. In vitro dissolution profile of waterinsoluble drug dosage forms in the presence of surfactants. Pharm. Res. 1989, 6, 612-618. DOI: 10.1023/A:1015909716312.

14. Park, S. H.; Choi, H. K. The effects of surfactants on the dissolution profiles of poorly water-soluble acidic drugs. Int. J. Pharm. 2006, 321, 35-41. DOI: 10.1016/j.ijpharm.2006.05.004.

15. Jena, S. K.; Singh, C.; Dora, C. P.; Suresh, S. Development of tamoxifen-phospholipid complex: novel approach for improving solubility and bioavailability. Int. J. Pharm. 2014, 473, 1-9. DOI: 10.1016/j.jpharm.2014.06.056.

16. Chen, L.; Zhu, L.; Li, M.; Li, N.; Qi, F.; Wang, N. Predicting the effects of different triazole antifungal agents on the pharmacokinetics of tamoxifen. AAPS PharmSciTech 2019, 20, 24. DOI: 10.1208/ s12249-018-1219-5.

17. Dissolution Testing of Immediate Release Solid Oral Dosage Forms; Guidance for Industry; U.S. Department of Health and Human Services, Food and Drug Administration, Center for Drug Evaluation and Research (CDER), U.S. Government Printing Office: Washington, DC, 1997.

18. Zhang, Y.; Huo, M.; Zhou, J.; Zou, A.; Li, W.; Yao, C.; Xie, S. DDSolver: an add-in program for modeling and comparison of drug dissolution profiles. AAPS J. 2010, 12, 263-271. DOI: 10.1208/s12248-010-9185-1.

19. In vitro and in vivo evaluation of dosage forms. In The United States Pharmacopoeia and National Formulary USP 30-NF 25; The United States Pharmacopeial Convention, Inc.: Rockville, MD, 2007, p 1088.

20. Incecayir, T. The effects of surfactants on the solubility and dissolution profiles of a poorly water-soluble basic drug, carvedilol. Pharmazie. 2015, 70, 784-790. DOI: 10.1691/ ph.2015.5081.

21. Physicians' Desk Reference, 50th ed. Medical Economics Data Production Co: Montvale, NJ, 1996; pp 2842-2844.

22. Peris-Vicente, J.; Carda-Broch, S.; Esteve-Romero, J. Quantification of tamoxifen in pharmaceutical formulations using micellar liquid chromatography. Anal. Sci. 2014, 30, 925-930. DOI: 10.2116/analsci.30.925.

23. Loftsson, T.; Vogensen, S. B.; Desbos, C.; Jansook, P. Carvedilol: solubilization and cyclodextrin complexation: a technical note. AAPS PharmSciTech 2008, 9, 425-430. DOI: 10.1208/s12249008-9055-7.

24. Bevernage, J.; Brouwers, J.; Brewster, M. E.; Augustijns, P. Evaluation of gastrointestinal drug supersaturation and precipitation: strategies and issues. Int. J. Pharm. 2013, 453, 25-35. DOI: 10.1016/j.jjpharm.2012.11.026.

25. Yu, L. X.; Amidon, G. L.; Polli, J. E.; Zhao, H.; Mehta, M. U.; Conner, D. P.; Shah, V. P.; Lesko, L. J.; Chen, M. L.; Lee, V. H. L.; Hussain, A. S. Biopharmaceutics classification system: the scientific basis for biowaiver extensions. Pharm. Res. 2002, 19, 921-925. DOI: 10.1023/a:1016473601633.

26. Balakrishnan, A.; Rege, B. D.; Amidon, G. L.; Polli, J. E. Surfactantmediated dissolution: contributions of solubility enhancement and relatively low micelle diffusivity. J. Pharm. Sci. 2004, 93, 2064-2075. DOI: 10.1002/jps.20118.

27. Galia, E.; Nicolaides, E.; Hörter, D.; Löbenberg, R.; Reppas, C.; Dressman, J. B. Evaluation of various dissolution media for predicting in vivo performance of class I and II drugs. Pharm. Res. 1998, 15, 698-705. DOI: 10.1023/A:1011910801212.

28. Klein, $\mathrm{S}$. The use of biorelevant dissolution media to forecast the in vivo performance of a drug. AAPS J. 2010, 12, 397-406. DOI: 10.1208/s12248-010-9203-3. 
29. Lehto, P.; Kortejärvi, H.; Liimatainen, A.; Ojala, K.; Kangas, H.; Hirvonen, J.; Tanninen, V. P.; Peltonen, L. Use of conventional surfactant media as surrogates for FaSSIF in simulating in vivo dissolution of BCS class II drugs. Eur. J. Pharm. Biopharm. 2011, 78, 531-538. DOI: 10.1016/j.ejpb.2011.02.007.

30. Polli, J. E.; Rekhi, G. S.; Augsburger, L. L.; Shah, V. P. Methods to compare dissolution profiles and a rationale for wide dissolution specifications for metoprolol tartrate tablets. J. Pharm. Sci. 1997, 86, 690-700. DOI: 10.1021/js960473x.

31. Cascone, S. Modeling and comparison of release profiles: Effect of the dissolution method. Eur. J. Pharm. Sci. 2017, 106, 352361. DOI: 10.1016/j.ejps.2017.06.021.

32. Hansten, P. D. The underrated risks of tamoxifen drug interactions. Eur. J. Drug Metab. Pharmacokinet. 2018, 43, 495508. DOI: 10.1007/s13318-018-0475-9.

33. Adam, H. K.; Patterson, J. S.; Kemp, J. V. Studies on the metabolism and pharmacokinetics of tamoxifen in normal volunteers. Cancer Treat Rep 1980, 64, 761-764.

34. Shin, S. C.; Choi, J. S.; Li, X. Enhanced bioavailability of tamoxifen after oral administration of tamoxifen with quercetin in rats. Int. J. Pharm. 2006, 313, 144-149. DOI: 10.1016/j. ijpharm.2006.01.028.

35. Takeuchi, S.; Tsume, Y.; Amidon, G. E.; Amidon, G. L. Evaluation of a three compartment in vitro gastrointestinal simulator dissolution apparatus to predict in vivo dissolution. J. Pharm. Sci. 2014, 103, 3416-3422. DOI: 10.1002/jps.24112.

36. Hens, B.; Sinko, P. D.; Job, N.; Dean, M.; Al-Gousous, J.; Salehi, N.; Ziff, R. M.; Tsume, Y.; Bermejo, M.; Paixão, P.; et al. Formulation predictive dissolution (fPD) testing to advance oral drug product development: An introduction to the US FDA funded '21st Century BA/BE' project. Int. J. Pharm. 2018, 548, 120-127. DOI: 10.1016/j.jpharm.2018.06.050.

37. Matsui, K.; Tsume, Y.; Amidon, G. E.; Amidon, G. L. In vitro dissolution of fluconazole and dipyridamole in gastrointestinal simulator (GIS), predicting in vivo dissolution and drug-drug interaction caused by acid-reducing agents. Mol. Pharm. 2015, 12, 2418-2428. DOI: 10.1021/acs.molpharmaceut.5b00135. 